Portland State University

PDXScholar

1992

\title{
Word retrieval behaviors of aphasic adults in conversational speech : a preliminary study
}

Priscilla Jane Blake

Portland State University

Follow this and additional works at: https://pdxscholar.library.pdx.edu/open_access_etds

Part of the Speech and Hearing Science Commons

Let us know how access to this document benefits you.

\section{Recommended Citation}

Blake, Priscilla Jane, "Word retrieval behaviors of aphasic adults in conversational speech : a preliminary study" (1992). Dissertations and Theses. Paper 4213.

https://doi.org/10.15760/etd.6097

This Thesis is brought to you for free and open access. It has been accepted for inclusion in Dissertations and Theses by an authorized administrator of PDXScholar. Please contact us if we can make this document more accessible: pdxscholar@pdx.edu. 
AN ABSTRACT OF THE THESIS OF Priscilla Jane Blake for the Master of Science in Speech Communication: Speech and Hearing Sciences presented November 16, 1992.

Title: Word Retrieval Behaviors of Aphasic Adults in Conversational Speech: A Preliminary Study.

APPROVAL BY THE MEMBERS OF THE THESIS COMMITTEE:

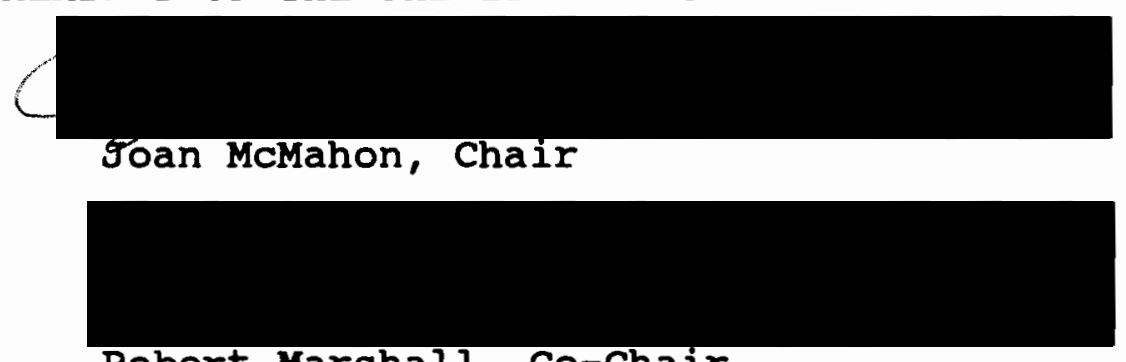

Robert Marshall, Co-Chair

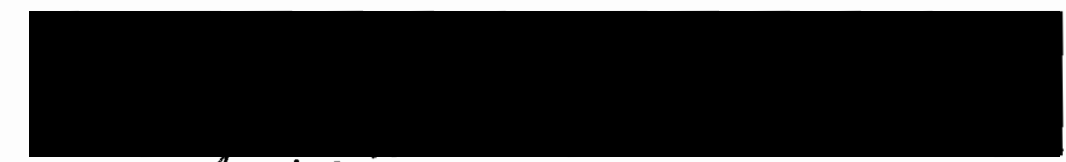

Mary T/f withers

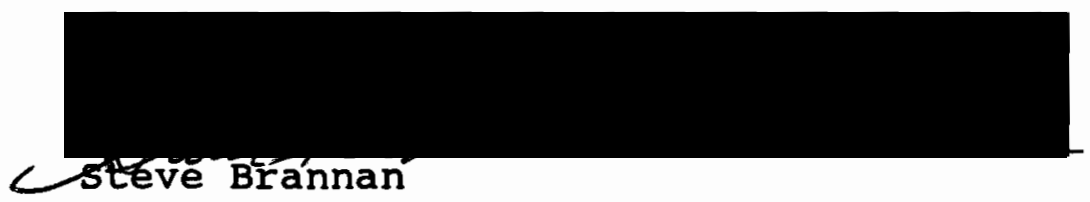

Word retrieval difficulties are experienced by almost all aphasic adults. Consequently, these problems receive a substantial amount of attention in aphasia treatment. Because of the methodological difficulties, few studies have examined WRBs in conversational speech, focusing instead on confrontational naming tasks in which the client is asked to retrieve a specific word. These studies have left 
unanswered questions about the WRB processes.

The purposes of this study were to: (1) develop profiles of WRB for moderately impaired aphasic adult clients and examine these profiles for evidence that reflects the level of breakdown in the word retrieval process, and (2) determine potential treatment applications derived from the study of WRBs of moderately aphasic speakers.

Five aphasic adult subjects from Portland Veterans Affairs Medical Center (PVAMC) participated in this study. These subjects were neurophysiologically stable, within the mid-range of severity and representative of three common aphasic syndromes, conduction aphasia (N=2), anomic aphasia $(\mathrm{N}=2)$, and Broca's aphasia $(\mathrm{N}=1)$.

Each subject participated in a video taped 15 minute conversation during which the experimenter introduced topics in the order specified from a list of topics. These conversations were then transcribed verbatim, and $50 \mathrm{~T}$-units were randomly selected for analysis. The types of WRBs employed by the subjects within each T-unit were identified and the following computations were made: (1) Total number of WRB for all T-units; (2) Percentage of T-units containing one or more WRB; (3) Number of WRBs for each category for all Tunits; (4) Percentage of T-units containing three or more WRBs and (5) Number of times in T-units containing three or more WRBs that led to evocation of a desired word or concept by the subject. 
WORD RETRIEVAL BEHAVIORS OF APHASIC ADULTS

IN CONVERSATIONAL SPEECH: A PRELIMINARY STUDY

by

PRISCILLA JANE BLAKE

A thesis submitted in partial fulfillment of the requirements for the degree of

MASTER OF SCIENCE

in

SPEECH COMMUNICATION:

SPEECH AND HEARING SCIENCE

Portland State University

1992 
TO THE OFFICE OF GRADUATE STUDIES:

The members of the Committee approve the thesis of Priscilla Jane Blake presented November 16, 1992.
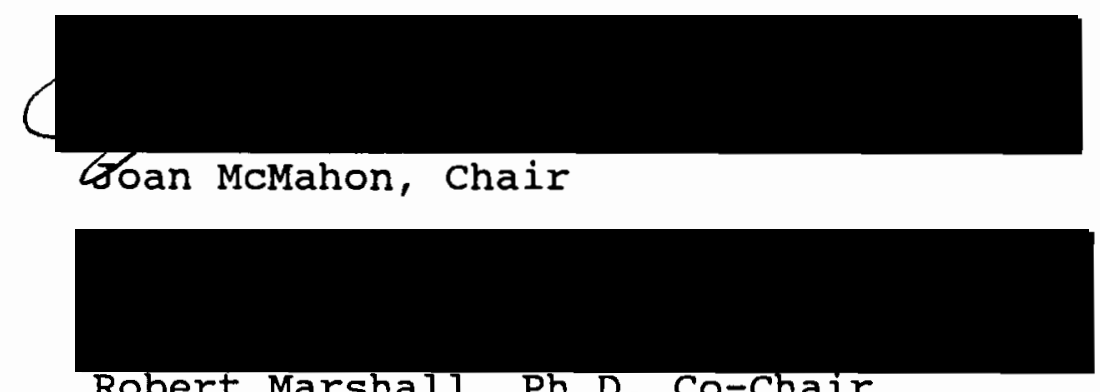

Robert Marshall, Ph.D. Co-Chair

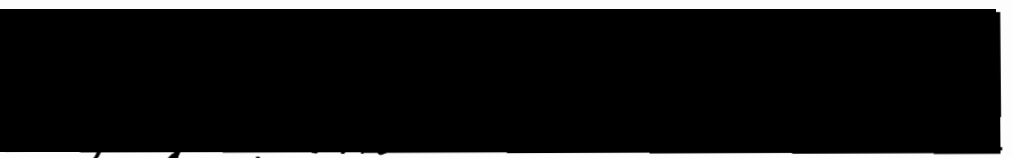

Mały Withers

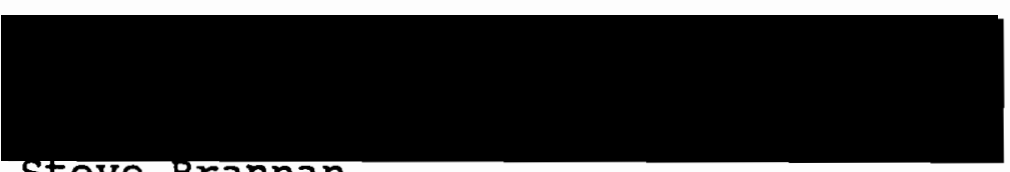

steve Brannan

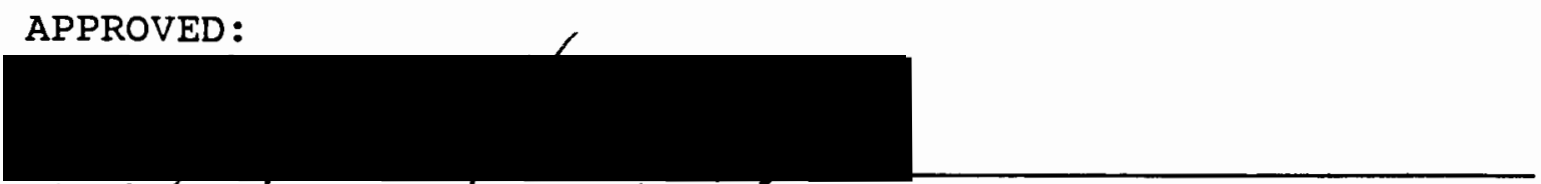

Stephén Al Kosokoff, Chair, Department of Speech Communication

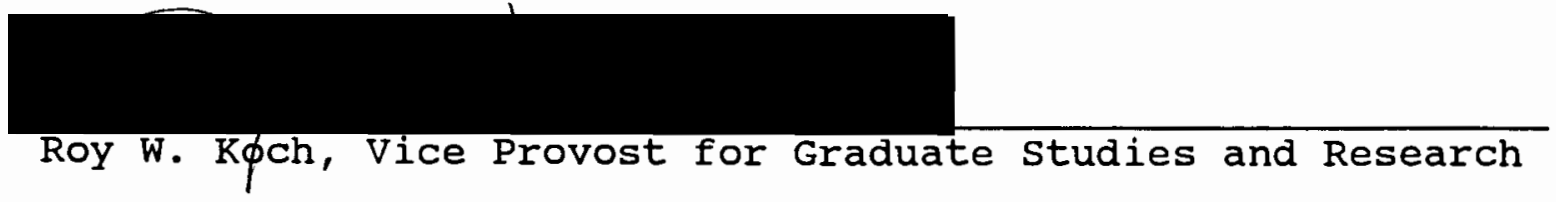


DEDICATION

This thesis is dedicated to you, Ocie stewart, where ever you are. 


\section{ACKNOWLEDGEMENT}

I am deeply indebted to Dr. Robert Marshall for the long hours of patient guidance and assistance he so graciously contributed to the completion of this thesis. Thank you so much.

I would also like to thank Dr. Steve Brannan, Joan McMahon, and Mary Therese Withers for agreeing to be on the committee. Little did they know what they were getting in to!

I also want to thank Terri and Bruce Elwood (and Alex too). Terri graciously consented to provide the interjudge reliability and spent many additional hours proof reading, number crunching, and providing encouragement.

I am also deeply indebted to Sylvia and Dick Smith. Throughout my undergraduate and graduate years, and thesis, Sylvia has typed and proofread my work, occasionally rescuing me at the "eleventh hour." Dick was always on standby with one of his wonderful Irish coffees.

If wealth is measured by the friends one has, I am very rich! 
TABLE OF CONTENTS

PAGE

ACKNOWLEDGEMENTS . . . . . . . . . . . . . . . . . iii

LIST OF TABLES . . . . . . . . . . . . . . . . . vii

CHAPTER

I INTRODUCTION . . . . . . . . . . . . . 1

Statement of Purpose. . . . . . . . . . 4

Terminology . . . . . . . . . . . 4

Anomic Aphasia

Broca's Aphasia

Conduction Aphasia

Confrontational Naming

II REVIEW OF THE LITERATURE . . . . . . • . . 6

Word Retrieval Process . . . . . . . 7

Indications of the Presence of word

Retrieval Difficulties. . . . . . . 8

Delays

Phonemic Paraphasias

Semantic Paraphasias

circumlocution

Neogisms

Treatment of Word Retrieval Deficits in

Confrontational Naming Versus Word

Retrieval in Conversational Speech . . 11

Specific Word Retrieval

General Stimulation

Patient Generated Response

Theraputic Implications of Word Retrieval

Behaviors . . . . . . . . . . 14 


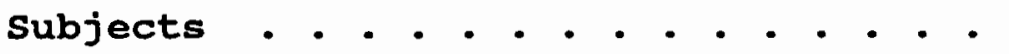

General subject selection criteria

Data Collections Methods. . . . . . 18

Physical setting and Recording

Role of Experimenter

Instructions to subject

Transcriptions of Conversational Periods. 20

Categorization of Word Retrieval

Behavior (WRB) . . . . . . . . . 20

Prolonged Pause

Time Filler

Combination Time Filler and Prolonged

Pause

Verbal Insertion

Request for Additional Time

Gestural or oral sound Insertion

Word or Phrase Reformulation

Word or Phrase Repetition

Articulatory Reformulation

Gesture or Mime

Recitation of Overlearned Sequences or Chaining

Description

Generalization

Unclassifiable

Computations. . . . . . . . . . . 24

Examiner Reliability . . . . . . . . 24

IV RESULTS AND DISCUSSION • • • • • • • • • • • • 27

Results . . . . . . . . . . . . . 27

Conduction Aphasia Subjects

Anomic Aphasia Subjects

Broca's Aphasia Subjects

Discussion of Individual subjects . . . 34

Conduction Aphasia

Anomic Aphasia

Broca's Aphasia 
General Discussion ......... . 40

$\mathbf{v}$

SUMMARY AND IMPLICATIONS $\cdot \cdot \cdot \cdot$
Summary $\cdot \cdot \cdot \cdot \cdot \cdot \cdot \cdot \cdot$
Implications $\cdot \cdot \cdot \cdot \cdot \cdot \cdot$
Clinical Implications
Research Implications

REFERENCES APPENDICES

A PORTLAND STATE UNIVERSITY PERMISSION LETTER • 51

B PORTLAND VA MEDICAL CENTER PERMISSION LETTER (STROKE SUBJECTS) . . . . . . . . . . . 53

C PORTLAND VA MEDICAL CENTER PERMISSION LETTER (SPOUSE/GUARDIAN) . . . . . . . . . . . 56

D CONVERSATIONAL PERIOD TOPICS . . . . . . . 59

E WORD RETRIEVAL BEHAVIORS DATA COLLECTION FORM. 61

F WORD RETRIEVAL BEHAVIORS NUMERICAL CODES • . . 64 


\section{LIST OF TABLES}

TABLE

PAGE

I Number of Word Retrieval Behaviors (WRBs) -Distribution of WRBs By Type For Individual Aphasic Subjects, and Mean Number of WRBs BY Type For Conduction ( $\mathrm{N}=2)$, Anomic $(\mathrm{N}=2)$ and Broca's $(\mathrm{N}=1)$ Aphasic Subjects . . . . . . . 25

II Number of T-Units containing WRB, Number of TUnits containing Three or More WRBs, and Number of Successful Retrieval Efforts in T-Units containing Three or More WRBs For conduction, Anomic, and Broca's Aphasic Subjects . . . . . 26 
CHAPTER I

\section{INTRODUCTION}

Aphasia is a language disorder resulting from brain injury (Benson \& Geschwind, 1964; Davis, 1983). This complex problem does not constitute a loss of language, but rather a deficit in the processing of language (Wiegel-Crump \& Koenigsknecht, 1973; Davis, 1983; Brookshire, 1986) that is manifested in both receptive and expressive modalities (Damasio, 1981). One of the primary processing deficits for most aphasic individuals involves accessing the lexicon or mental dictionary (Goodglass \& Blumstein, 1973; Buckingham, 1981) as they attempt to retrieve a desired word on a confrontation naming task or in conversation (Davis, 1983). Aphasia clinicians refer to this processing deficit as a "word retrieval or "word finding" problem. It has been compared to the difficulty that normal individuals exhibit when recalling a specific word or name, and the frustration we all experience when a desired word is on the "tip of our tongue" (Davis, 1983). One must magnify this situation many times over to understand the degree of frustration endured by the aphasic individual. These deficits not only disrupt communication, but they affect the individual's life in many ways, frequently leading to feelings of helplessness and 
loss of confidence (Eisenson, 1973; Sarno, 1981; Norlin, 1986).

It has been observed that aphasic individuals behave differently and appear to employ different strategies as they attempt to retrieve a desired word. These word retrieval behaviors (WRBs) take the form of delays (silent pauses and pauses filled with interjections such as "um," "er," etc.) (Buckingham, 1981; Marshall, 1976) and production of words that are semantically related (wife for husband) or phonologically related (patches for matches) to the target word (Code, 1989; Blumstein, 1981; Davis, 1983). Additionally, aphasic adults may describe the intended concept (e.g. the kind of dancing when they are on their toes/ballet), circumlocute (talk around the word) (Davis, 1983) or substitute indefinite pro-forms such as "thing," "one," and "it" for the target word (Buckingham, $1981 \mathrm{p}$. 195) •

Sometimes WRBs of aphasic individuals provide sufficient information to allow the listener to determine the intended target word; conversely, other clues provided by the patient's description, circumlocution, or use of related words are too general to permit the listener to guess the intended target (Tompkins \& Marshall, 1982). It has also been shown that various forms of word retrieval behavior will at times culminate in the production of the desired word while other times they do not (Berman \& Peele, 
1967). These kinds of behaviors may be considered as forms of self-cueing efforts on the part of the patient as he/she attempts to come up with a specific word (Davis, 1983) and may have theraputic application. For example, those WRBs which are shown to have a high degree of success could be taught, while those WRBs which show a low degree of success could be discouraged.

Marshall (1976) examined 740 instances of aphasic word retrieval behaviors generated by 18 aphasic adults during conversational speech. In his study, Marshall defined operationally five types of word retrieval behavior: delay, semantic association, phonetic association, description, and generalization and determined (1) the frequency of occurrence of each behavior and (2) the success with which particular behaviors resulted in production of the target word. The behavior most likely to result in evocation of the target word was delay, defined by Marshall as the patient taking or asking for extra time. The behavior least likely to result in production of the intended target word was generalization.

Marshall (1976) concluded that data concerning the WRBs of aphasic adults would be more informative if future studies analyzed these behaviors according to type of aphasia and degree of severity. The present study will replicate and expand Marshall's study by examining the word retrieval behaviors observed during the conversational 
speech of aphasic adults who are within the mid-range of severity and represent one of three specific aphasia types, namely, Broca's, Conduction, and Anomic aphasia.

\section{STATEMENT OF PURPOSE}

The primary focus of the proposed study is to determine the type and communicative value of the self-generated word retrieval behaviors aphasic adults employ during conversational speech. Answers to the following questions will be sought: 1 . How often is each specific WRB employed by Conduction, Anomic and Broca's aphasic adults? 2. Do some WRBs result in production of the desired word more often than others for each of the three types of aphasia?

\section{TERMINOLOGY}

The following terms will be used for the purpose of this research:

\section{Anomic Aphasia}

Characterized by persistent word-finding difficulty in the context of fluent, grammatically well-formed speech and intact auditory comprehension (Nicolosi, Harryman \& Kresheck, 1989). Speech is free flowing but there is a pronounced lack of substantive words which are sometimes replaced with general words such as "thing" or "those" (Goodglass \& Kaplan, 1983). 


\section{Broca's Aphasia}

Characterized by a reduced ability to initiate sound sequences within words. Articulation is awkward and effortful and prosody may sound mechanical. Vocabulary is limited and consists mainly of high-frequency words and overlearned grammatical constructions. Auditory comprehension is relatively intact (Goodglass \& Kaplan, 1983; Kearns, 1990).

\section{Conduction Aphasia}

Individuals with conduction aphasia demonstrate a severe inability to repeat which is disproportionate to their level of fluency in spontaneous speech ( $\mathrm{Nicolosi}$ et al., 1989; Simmons, 1990). There are well-articulated runs of speech, with normal intonation and variation in syntactic patterns. Literal paraphasic errors are common and attempts at correction are frequent. Auditory comprehension is relatively normal (simmons, 1990).

\section{Confrontational Naming}

Production of the specific name of an object or picture of an object upon direct request (Davis, 1983). 
CHAPTER II

REVIEW OF THE LITERATURE

The literature review begins with a definition of acquired aphasia and a brief description of the language specific cognitive system. Two major word retrieval theories will be presented, followed by a description of behaviors which indicate the presence of aphasic word retrieval difficulty and the therapeutic implications such word retrieval behaviors (WRBs) may possess. A comparison of word retrieval as it related to confrontational naming and conversational speech will be provided, followed by a review of treatment types developed to date.

Aphasia, according to David (1983) is "an acquired impairment of language processes underlying receptive and expressive modalities and caused by damage to areas of the brain which are primarily responsible for language function" (p. 1). The primary deficit underlying the aphasic person's communicative problem is the inability to process language manifested by a reduction in the ability to understand spoken or written language and to express ideas through the use of language in written or spoken form (Schuell \& Jenkins, 1961; Darley, 1982; Wertz, 1984). The aphasic person, therefore, reflects a decreased ability to send or 
receive conversational messages thus restricting his or her ability to interact with the environment (Davis, 1983).

\section{WORD RETRIEVAL PROCESS}

The inability to process language has puzzled researchers for over a century. As more is learned about the brain, it has become evident that the localizing of specific cognitive functions within specific brain structures was premature (Wepman, Jones, Bock \& Van Pelt, 1960; Schuell \& Jenkins, 1961; Code 1989). The simple tasks of naming an object or picture, for instance, may involve a vast array of cognitive functions including numerous subsystems and the complex interactions between these subsystems (Code, 1989).

As early as 1890, william James discussed word retrieval as the process of searching unsuccessfully for a word for which parts of that word may be available, but being able to correctly identify that word from a outside source (Goodglass, Wingfield, \& Wayland, 1989). Lesser (1987) described the word retrieval process as a sequence of events occurring in a specific order. The process, she believes, begins with the accurate selection of the word from the semantic lexicon. There, vital information about both the connotative (emotional) and denotative (symbolic) components of the word are retrieved. The individual's "knowledge of the world" which has been acquired through 
life experience also contributes to the process or word retrieval.

Once selected, the word is formulated into its phonological shape within the phonological lexicon. At this point, the selection and orderly arrangement of the phonemic information is required to produce the word occurs. This phonemic information is then translated into the phonetic pattern of the word desired. Finally, the phonetic representation of the word is transposed into the motor movements needed to produce the appropriate articulatory configurations required to correctly produce the word (Lesser, 1987).

INDICATIONS OF THE PRESENCE OF WORD RETRIEVAL DIFFICULTIES

\section{Delays}

Increased latencies may indicate that the aphasic person is experiencing difficulty retrieving a word from the lexicon. Selection of the specific word takes time and does not occur until after the grammatical category of the target form has been selected (Buckingham, 1981). Delays include filled pauses (e.g., "um uh, what am I trying to say"), talking (e.g., turning the head away or tapping the table), or silences. Such behaviors alert the listener that the speaker does not want to be interrupted and needs more time to produce the word (Marshall, 1986). 


\section{Phonemic Paraphasias}

Phonemic paraphasias reflect errors in which the aphasic person's verbal productions are related in sound structure to the word intended (Buckingham, 1981). The aphasic person may rearrange erroneously (e.g., dear a book), add a phoneme (e.g., dread a brook), or substitute phonemes (e.g., read a dook) resulting in what are called malapropisms (Buckingham, 1981; Goodglass \& Blumstein, 1973). These errors occur when the client has difficulty sequencing the phonemes of a word and may be anticipatory or reiterative errors (Farmer, O'Connell, \& O'Connell, 1978). Marshall (1976) suggests that these behaviors exhibited by the apraxic individual, but instead resembles behaviors considered to be "slips of the tongue" or spoonerisms.

\section{Semantic Paraphasias}

Semantic paraphasias occur when the selection of items from the lexicon is disordered (Buckingham, 1981). At times, the aphasic person substitutes a word that is semantically related to the desired word (e.g. the sky is red; lemons are sweet) (Benson \& Geschwind, 1964; Buckingham, 1981; Nicolosi et al., 1989). Semantic errors occur during the psychological process of retrieving a specific word from the lexicon. They may reflect a breakdown in hierarchical relationships or point of minimal set contrast (e.g., dog - cat, television - radio) (Buckingham, 1981). While these aphasic errors also occur 
in normal speakers, they occur more frequently and are less apt to be corrected (Davis, 1983).

\section{Circumlocution}

Circumlocutions also indicate that the aphasic person is having difficulty accessing the lexicon. The individual may use indefinite terms and vague expresstions which are best described as empty speech (Buckingham, 1981). An example of this behavior would be a phrase or sentence such as "the thing you use to do all that stuff with."

\section{Neologisms}

Neologisms are phonetically transcribable non-words which do not occur within the language being spoken (Nicolosi et al, 1989). Because of their novelty, they are more identifiable than semantic paraphasias. Neologisms may result from a deficit in the ability to compose a word phonologically to such an extent that the target word is unrecognizable (e.g., "pishpog" for "cigarette") (Goodglass \& Kaplan, 1983; David, 1983). A second explanation for neologistic utterances is that the word selected for production may be incorrect itself, and may be coupled with a phonemic paraphasia resulting in a "two-stage" error (e.g., "typesitter" for "telephone"). A third plausible explanation is that segments from an earlier neologistic production may appear perseveratively in the current word production (e.g., "cart the cartbook"). Similarly, 
variations of a particular word form or syllable configuration may contain perseverative use of one specific affix (e.g., "thusly and loosely") (Davis, 1983). A fourth possible neologistic form occurs when the ability to retrieve a word is completely blocked. In this case, the word is replaced by a series of well-formed phonemes or syllables which are used to "fill the gaps" caused by the aphasic person's inability to retrieve the desired word from the lexicon (e.g., "bish bo bish bo bishbo") (Buckingham, 1981).

TREATMENT OF WORD RETRIEVAL DEFICITS IN CONFRONTATIONAL NAMING VERSUS WORD RETRIEVAL IN CONVERSATIONAL SPEECH

Confrontational naming, in which the aphasic adult is required to name a picture or object, has long been used to assess word-retrieval deficits. Unfortunately, the conditions under which a word is retrieved in a naming task differ from those for conversation. Stimuli employed in naming tasks must be picturable, and typically, these frequently used words represent commonly used, highfrequency items. The word "table," for example, can be illustrated in picture form. "Furniture," on the other hand, is not a picturable word (Davis, 1983).

Another difference between confrontational naming spontaneous speech lies in the fact that during conversation, the desired word is retrieved in a context. The speaker is able to select a word of his choosing (e.g., 
tie the package with a ribbon, bow, string, twine) as long as the word fits the context. The naming of a specific object, in contrast, lacks such contextual influences and the number of appropriate responses is limited (Davis, 1983). Still another element for consideration is that when attempting a specific word retrieval task, the aphasic individual is struggling to attain accuracy in word-finding and the search for ideas is limited (Wepman, 1972). Object naming, therefore, is dissimilar to the word retrieval process found in conversational speech (Davis, 1983).

Aphasic treatment seeks to "facilitate desired behavior, prevent maladaptive behavior, and reorganize impaired language skills" (Wertz, 1985, p. 27). Most treatment procedures fall into three categories; specific word retrieval, general stimulation, and patient generated responses.

\section{Specific Word Retrieval}

The emphasis of this type of remediation is to assist the aphasic person in increasing the ability to produce specific words using cues from the clinician, or originally developed by the client (self cues). These treatment styles have overlooked the need to improve the overall ability to convey information and focused instead on attaining a specific linguistic response (Wepman, 1982, Tompkins \& Marshall, 1981). A common form of this type of remediation is the development of a cueing hierarchy which elicits 
single words in both confrontational naming and sentence completion tasks (Brookshire, 1986; Gardfarb \& Halpern, 1989)

\section{General stimulation}

Although direct therapy in which specific responses are elicited proved to be of some value, general stimulation therapies of a nonspecific nature seem to be more effective (Wepman et al, 1960). Wepman (1972, 1976), a leader in this school of thought, believed that aphasia was an impairment of thought processing, and that treatment should focus on the embellishment of thought rather than the teaching of specific vocabulary and syntax. He supported the theory that the principal form of remediation should therefore be receptive and expressive language stimulation. Some general stimulation approaches to remediation address language processing as an active problem-solving task (Chapey, 1986). Others emphasize lexicon access (Seron, Deloche, Baster, Chassin, \& Herman, 1979).

\section{Patient Generated Response}

Few treatment approaches have focused on patient generated responses. Davis and wilcox (1985) looked at adult aphasia rehabilitation within an unrestricted and natural pragmatic framework. They believed that the sociolinguistic aspects of conversational speech which includes the participants, topic, and setting must be taken 
into consideration in aphasia therapy. They stress encouraging the client to convey information through the communicative channel of his or her choice. Primary focus of treatment, therefore, lies in improving the client's overall ability to convey information rather than seeking to improve his or her symbolic adequacy.

THERAPEUTIC IMPLICATIONS OF WORD RETRIEVAL BEHAVIORS

It has been found that in some instances, the WRBs aphasic adults exhibit while attempting to retrieve a word may ultimately trigger its correct production. In fact, the communicative efficiency of some aphasic people could be improved by providing them with an awareness of the efficacy of these behaviors (Berman \& Peele, 1967).

Alajouanine (1954) described the speech behaviors of the aphasic individual as they evolve over a period of time. He believed that these behaviors progress through a series of word approximation stages until the earlier stereotypical utterances are later replaced by slow agrammatic speech whose imperfections the individual readily recognizes and attempts to correct. Barton (1971) found that aphasic people can give information about the word they are searching for at better than chance level. Wepman (1976), in fact, was convinced tht the assessment of self-correction behaviors is an important part of the development of a prognosis for adult aphasia. Marshall and Tompkins (1982) 
suggest that aphasic self-correction behaviors are performed without awareness of what the person is doing are "a behavioral reaction to an erroneous response, or dissatisfaction with the quality of the response" (p. 303). Tompkins and Marshall (1982) suggested that it might be helpful to develop an awareness of the types and significance of the self-correction behaviors aphasic people employ in their attempt to retrieve the desired word. Such information, they believe, could then be used to "devise strategies to encourage or discourage the use to these behavior" (p. 172).

These findings confirm the observations made by aphasia clinicians that aphasic people often are able to convey by gesture, association, circumlocution, or description that they have an awareness of the concept they are unable to express in speech (Marshall, 1976).

In a study of aphasic word retrieval strategies, Marshall (1976) found that semantic associations and descriptions were the behaviors which occurred most frequently. There were followed by phonetic associations, delays and generalization, which occurred with similar frequency. Semantic and descriptive behaviors were far less likely to elicit a correct response $(56 \%$ and $34.5 \%$ respectively) than delay which proved to be effective $90.6 \%$ of the time. Marshall also noted a relationship between the severity of communicative impairment and the word retrieval 
strategies implemented. Higher level subjects were more apt to use delay as a strategy for word retrieval. Marshall concluded that the associations employed by aphasic individuals when searching for a word may be related to how close the person is to actually retrieving the word. It may be possible to teach such associational behaviors to aphasic individuals so that their word retrieval efficiency during conversation would be improved (Berman \& Peele, 1967; Marshall, 1976).

Farmer (1977) investigated the success of aphasic subjects' self-correctional strategies in conversational speech. She divided her subjects into four categories; Broca's, anomic, conduction, and Wernicke's aphasia. Findings indicated that delay was the most successful strategy for all subjects. The next most successful strategy (for both Broca's and Wernickes' aphasics) was association (production of semantically related word, e.g., puppy/kitten), and sound revisions (e.g., tu tu tug tote tugboat) ranked third. The second most successful strategy for anomic and conduction aphasics was sound revision with association ranking third. Description, (e.g., the thing you put on your foot), and generalization (use of "empty" or general words (e.g., this, it) were least successful for all groups. 
CHAPTER III

METHODS

SUBJECTS

Six subjects originally participated in this study. One Broca's aphasic subject was excluded due to an inability to produce sufficient fluent speech for analysis. Five aphasic adult males from Portland Veterans Affairs Medical Center (PVAMC) participated in this study. They were neurophysiologically stable, within the mid-range of severity and represented three common aphasic syndromes as identified by the Boston Diagnostic Aphasia Examination (BDAE) - Types of aphasia represented in this study were: conduction aphasia $(\mathrm{N}=2)$, anomic aphasia $(\mathrm{N}=2)$, and Broca's aphasia $(\mathrm{N}=1)$

\section{General Subject Selection Criteria}

General selection criteria met by all consenting subjects (Appendices A, B, C) included the following:

1. Right handed

2. Duration of aphasia at least six months post onset

3. Age range 49-79 years

4. Lesion confined to left hemisphere as specified by CAT or MRI scan. 
5. Classification of subjects' aphasia types was based on profiles from the BDAE (Goodglass \& Kaplan, 1983).

6. Severity of aphasia between the 50th and 89th over all percentile ranking on the Porch Index of Communicative Abilities (PICA) (Porch, 1981).

7. Must produce efficient fluent speech to participate in a conversation.

DATA COLLECTION METHODS

Each subject participated in a 15 minute conversation scheduled at a time chosen by each of the subjects when he felt he would be talking "at his best." The conversation was recorded on video and audio tape. During the conversation, the experimenter introduced topics in order from a specific list of topics (see Appendix D). Each conversation was transcribed verbatim by the experimenter for subsequent scoring and analysis.

\section{Physical setting and Recording}

All conversations took place in a speech pathology treatment room at PVAMC. An experienced examiner sat across the table from the subject and conducted the conversation. A video camera was focused on the subject in a full face/body position. The video monitor was turned of to prevent the subject from becoming distracted. An audio recording was also made as a back up. 
Role of Experimenter

The experimenter operated the recording equipment and instructed the subject about his participation in the study. The examiner initiated conversational topics in the order listed in Appendix $D$ and kept the subject engaged in conversation until the 15 minute period had elapsed. The examiner's role was to keep the subject focused on the conversational topic being discussed, and to provide encouragement. When the subject clearly acknowledged that he could not find a specific word, the examiner supplied it for him, and/or instructed the subject not to worry about it and to move on. When the subject indicated he had exhausted the topic at hand, a new topic was introduced. Although subjects took different amounts of time with each topic, the same order of topic sequences was used for each subject.

\section{Instructions to subject}

Before beginning the conversation, the examiner talked with the subject for 2 to 3 minutes to help him adjust to the experimental setting. The subject was then read the following instructions:

Sometimes persons who have had a stroke have problems thinking of the words they want to use in a conversation. We call this a word finding difficulty. At times, it seems as if that special word is on the "tip of our tongue" but it just won't come out. If we talk about the word by describing it, try to substitute a new word, or take our time, sometimes the word pops out. other times, it doesn't. The ways individual people try to find words are unique and this is what we are trying to study. Can you think of a word that was 
troublesome for you in the last few days? (At this point, the experimenter discusses what the subject did in an attempt to retrieve the word.) Today, I am interested in what you do when you are trying to find certain words as you participate in a conversation. I know that speech therapists and sometimes our wife/husband and friends are helpful in guessing the missing word and they try to help us. But today, I will not help you. I want you to try to come up with the word on your own. It's fine for you to tell me you are having difficulty. If you just can't seem to come up with the needed word after trying your best, let me know and we'll move on. Because I need to go back over all your conversation, I will record what we say today. Remember, there are no scores. No good and bad performances here. What you help us learn will be useful to other stroke victims. Do you have any questions? Are you ready to begin?

\section{TRANSCRIPTIONS OF CONVERSATIONAL PERIODS}

The subject's and the examiner's verbalizations were transcribed verbatim by the experimenter. All non-standard verbalizations, paraphasic errors, imprecise or colloquial pronunciations of words, and non-words emitted by both the examiner and the aphasic subject were transcribed using the international phonetic alphabet (IPA). After transcription accuracy was ensured, 50 T-units were randomly selected from each subject's transcription. A T-unit is defined as the briefest, gramatically correct unit which can begin with a capital letter and end with a period (Hunt, 1965; Scott, 1988). Instances of WRBs within the $50 \mathrm{~T}$-units were identified, categorized, and recorded on the word Retrieval Behavior Data Collection Form (see Appendix E). One Broca's aphasic subject was not included because of the inability to 
produce complete T-units.

CATEGORIZATION OF TYPES OF WORD RETRIEVAL BEHAVIOR (WRB)

Six WRBs were considered a form of delay. The subject was either silent, or conveyed to the listener that he was attempting to retrieve the word or phrase. These behaviors were operationally defined as follows:

\section{Prolonged Pause}

Subject pauses for 6 seconds or more before continuing on. Instances of inappropriate pauses of any length were transcribed by using the \# symbol (e.g., they \# drove).

\section{Time Filler}

Subject produces three or more, one, two, or three phoneme utterances, some of which may be non-words (e.g., "uh," "um," or "like").

Combination Time Filler and Prolonged Pause

Episode in which subject combines prolonged pauses and time fillers for a period of 6 seconds or more (e.g.," \# oh \#" or "uh \# like \# uh \#").

\section{Verbal Insertion}

Subject interjects an utterance which indicates an inability to produce the desired word or phrase. This utterance may signify frustration or dissatisfaction with the response (e.g., "God damn," or "It won't come out" or 
"no, I mean").

Request for Additional Time

Subject requests additional time to produce the desired word or phrase (e.g., "Let me think," or "Just a minute").

Gestural or oral sound Insertion

subject indicates difficulty producing a word or phrase by engaging in behaviors such as closing eyes and shaking head "no," tapping table, whistling, or producing a clicking noise with tongue.

Operational definitions for other WRBs are as follows:

\section{Word or Phrase Reformulation}

Subject reformulates a word or phrase with another word or phrase of similar meaning. In some instances, a portion of the word (e.g., "five 'mu' five years,") a whole word (e.g., "taking my money, taking their money" or a phrase (e.g., "It was on his, oh kind of on the east") may be produced.

\section{Word or Phrase Repetition}

subject repeats verbatim a word or phrase previously produced (e.g., "and and" or "right on the, right on the border").

\section{Articulatory Reformulation}

One or more attempts to produce the word that has previously been articulated correctly or incorrectly (e.g., 
"Jordan [gフr] Jordan" or "di, dimkins, democracy").

\section{Gesture or Mime}

Subject demonstrates with gesture or pantomime the desired concept (e.g., pretends to use calculator or taking money and putting it in pocket).

Recitation of Overlearned Sequences or Chaining

Subject produces a sequence of over learned words or phrases in order to retrieve a desired word or phrase (e.g., "one, two, three, four weeks").

\section{Description}

Subject describes the intended word in terms of its function and form, and/or provides specific directions to the listener to convey knowledge of the missing word (eg., "the person that throws the ball" or "the little country right on the border" or "it starts with an N").

\section{Generalization}

Subject uses vague, inadequate or indefinite word pro-forms in place of the intended word (e.g., thing, stuff, those, or "the big boys").

\section{Unclassifiable}

subject behaviors which cannot be accurately placed in a specific category. 
COMPUTATIONS

The following computations were made. Table I shows (1) total number of WRBs for $50 \mathrm{~T}$-unit samples for T-units, and (2) number of WRBs for each subject and mean for each aphasic syndrome. Table II shows (1) number of T-units containing one or more WRB, (2) number of T-units containing three or more WRBs, and (3) number of times T-units containing three or more WRBs that led to evocation of a desired word or concept by the subject. Inability to retrieve a word was determined by one or more of the following behaviors: subject asked for help, subject indicated displeasure, or the experimenter made a subjective evaluation. Because determining if a single WRB is caused by an aphasic deficit, or is merely a normal nonfluency, only those T-units containing three or more instances of WRBs were analysed for word retrieval success.

EXAMINER RELIABILITY

To ensure reliability of the classification procedures of WRBs, a speech-language pathologist (judge) unfamiliar with the subjects or the experiment reviewed $15 \mathrm{~T}$-unit sections randomly chosen from the $50 \mathrm{~T}$-unit transcripts and their corresponding videotapes for each subject. The judge coded each WRB using the list of WRB numerical codes as a guide (Appendix F). Point-to-point comparison of the categorizations of the experimenter and the judge resulted 
in $90 \%$ interjudge agreement. Intra-experimenter agreement for categorization of WRBs resulted in $96 \%$ agreement when the original experimenter recategorized 15 randomly choosen T-units two weeks following the first categorization session.

\section{TABLE I}

NUMBER OF WORD RETRIEVAL BEHAVIORS (WRBS) --

DISTRIBUTION OF WRBS BY TYPE FOR INDIVIDUAL APHASIC SUBJECTS, AND MEAN NUMBER OF WRBS BY TYPE FOR CONDUCTION $(\mathrm{N}=2)$, ANOMIC $(\mathrm{N}=2)$ AND BROCA'S $(\mathrm{N}=1)$ APHASIC SUBJECTS

\begin{tabular}{|c|c|c|c|c|c|c|c|}
\hline & \multicolumn{3}{|c|}{ Conduction } & \multicolumn{3}{|c|}{ Anomic } & \multirow{2}{*}{$\begin{array}{l}\text { Broca's } \\
\text { S5 }\end{array}$} \\
\hline & S1 & S2 & $\mathrm{x}$ & s3 & 54 & $\mathrm{x}$ & \\
\hline Total WRB & 140 & 52 & 96 & 62 & 62 & 62 & 119 \\
\hline Prolonged Pause & 0 & 0 & 0 & 0 & 1 & 0.5 & 1 \\
\hline Time Filler & 15 & 0 & 7.5 & 8 & 2 & 5 & 5 \\
\hline $\begin{array}{l}\text { Combination Time } \\
\text { Filler and } \\
\text { Prolonged Pause }\end{array}$ & 1 & 0 & 0.5 & 3 & 0 & 1.5 & 1 \\
\hline Verbal Insertion & 13 & 11 & 12 & 6 & 4 & 5 & 12 \\
\hline $\begin{array}{l}\text { Request for } \\
\text { Additional Time }\end{array}$ & 0 & 0 & 0 & 0 & 0 & 0 & $\overline{0}$ \\
\hline $\begin{array}{l}\text { Gesture or Oral } \\
\text { Sound Insertion }\end{array}$ & 2 & 0 & 1 & 3 & 0 & 1.5 & 2 \\
\hline $\begin{array}{l}\text { Word or Phrase } \\
\text { Reformulation }\end{array}$ & 39 & 15 & 27 & 29 & 29 & 29 & 39 \\
\hline $\begin{array}{l}\text { Word or Phrase } \\
\text { Repetition }\end{array}$ & 26 & 9 & 17.5 & 6 & 7 & 6.5 & 27 \\
\hline $\begin{array}{l}\text { Articulatory } \\
\text { Reformulation }\end{array}$ & 21 & 15 & 18 & 0 & 16 & 8 & 18 \\
\hline Gesture or Mime & 0 & 0 & 0 & 0 & 0 & 0 & 3 \\
\hline $\begin{array}{l}\text { Recitation of } \\
\text { overlearned } \\
\text { Sequences or } \\
\text { Chaining }\end{array}$ & 0 & 0 & 0 & 1 & 0 & 0.5 & 0 \\
\hline Description & 8 & 0 & 4 & 5 & 2 & 3.5 & 4 \\
\hline Generalization & 13 & 1 & 7 & 0 & 1 & 0.5 & 7 \\
\hline Unclassifiable & 2 & 1 & 1.5 & 1 & 0 & 0.5 & 0 \\
\hline
\end{tabular}


TABLE II

NUMBER OF T-UNITS CONTAINING WRBS, NUMBER OF T-UNITS CONTAINING THREE OR MORE WRBS, AND NUMBER OF SUCCESSFUL RETRIEVAL EFFORTS IN T-UNITS CONTAINING THREE OR MORE WRBS FOR CONDUCTION, ANOMIC, AND BROCA'S APHASIC SUBJECTS

\begin{tabular}{||l|cc|cc|c||}
\hline & \multicolumn{2}{|c|}{ Conduction } & \multicolumn{2}{|c|}{ Anomic } & Broca's \\
& Subj. 1 Subj. 2 & Subj. 3 Subj. 3 & Subj. 5 \\
\hline \hline $\begin{array}{l}\text { Total T-Units } \\
\text { containing 1 or } \\
\text { more WRBs }\end{array}$ & 34 & 23 & 19 & 28 & 29 \\
\hline $\begin{array}{l}\text { T-units with 3+ } \\
\text { WRBs }\end{array}$ & 20 & 7 & 10 & 10 & 17 \\
\hline $\begin{array}{l}\text { T-units with 3+ } \\
\text { WRBs where target } \\
\text { word successfully } \\
\text { retrieved }\end{array}$ & 9 & 9 & 8 & 10 & 7 \\
\hline
\end{tabular}




\section{CHAPTER IV}

\section{RESULTS AND DISCUSSION}

\section{RESULTS}

Data were not amenable to statistical analysis because of the limited number of subjects and the variability among subjects' word retrieval skills.

The first question in this study asked: How often is each type of specific WRB employed by adults who have conduction, anomic, or Broca's aphasia? Table I shows the total nmber of WRBs for the conduction $(\mathrm{N}=2)$, anomic $(\mathrm{N}=2)$, and Broca's ( $\mathrm{N}=1$ ) aphasic subjects, and the distribution of WRB forms for the 14 WRB categories. WRB totals were averaged for the conduction and anomic subjects to provide group means. Table I shows that four types of WRBs, word or phrase reformulations, verbal insertions, word or phrase repetitions, and articulatory reformulations constituted the most frequently used WRBs of all types. The conclusions that can be drawn from the limited data available is that the three aphasic types do not differ markedly in the types of WRBs used in retrieving with a desired word.

The second question asked if some WRBs result in production of the desired word more often than others for each of the three aphasia types. WRBs were analyzed in 50 
T-units taken from a conversational sample of two conduction, two anomic, and one Broca's aphasic subjects. Table II gives the number of T-units containing any type of WRB, the number of T-units containing three or more instances of WRB, and the number of times the "target word" was successfully retrieved in T-units with three or more WRBs for each subject.

Table II shows that in those T-units containing three or more WRBs, the two anomic subjects were more successful in retrieving the intended target word. Anomic subject 1 was successful $80 \%$ of the time; anomic subject 2 was successful $100 \%$ of the time. Conduction aphasic subjects and the one Broca's subject retreived the intended target word about half of the time, and failed to do so about half of the time. It was not possible to determine whether use of specific WRBs led to production of the target word for several reasons. First, there were several T-units where subjects had only one or two WRBs. These seemed to disrupt speech fluency, but did not affect word retrieval success. Secondly, the types of WRBs demonstrated by all subjects did not differ markedly. Thus, it is not possible to answer question two from the limited data available.

\section{Conduction Aphasia Subjects}

The two conduction aphasic subjects produced a total of 192 WRBs which represened $44 \%$ of the total WRBs for all subjects. Fifty-four of these behaviors were word or phrase 
reformulation, with a mean of 27 . Articulatory reformulations accounted for 36 of the behaviors, with a mean of 18. Other WRBs that showed a high frequency of occurrence were word or phrase repetition, 35 with a mean of 17.5 ; verbal insertion, 24 with a mean of $12 ;$ and time filler, 15 with a mean of 7.5 .

Subject 1. Medical History. Subject 1 is a 49 year old conduction aphasic male. In 1986, he suddenly developed aphasia, without accompanying weakness or numbness. Contrast and noncontrast CT scans revealed a new infarct area in the left parietal-occipital region, felt to be the result of an embolic stroke. Subject 1 was 55 months post onset at the time of his participation in this study.

Speech/Language Data. Subject $1^{\prime}$ s overall percentile ranking on the PICA placed him at the 88 th percentile in a large random sample of left hemisphere damaged adults. His rating of 3 on the Aphasia Severity scale of the Boston Diagnostic Aphasia Examination (BDAE) (Goodglass \& Kaplan, 1983), suggested that "he can discuss almost all everyday problems with little-to-no assistance, but reduction of speech and/or comprehension makes conversation about certain topics difficult."

Word Retrieval Data. Subject 1 produced a total of 140 WRBs. These occurred in 34 (68\%) of the T-units. Twenty (38\%) T-units contained three or more WRBS (see tables 1 \& 2). 
Subject 1 has problems at three stages of the word retrieval process; semantic lexicon, phonological lexicon, and phonological assembly. Processing delays (e.g., time fillers, verbal insertions, and word or phrase repetitions) suggest difficulties in retrieving a word from the semantic lexicon. Difficulties in mapping items from the semantic lexicon on to their phonological shapes in the phonological lexicon were seen with "tip of the tongue" phenomenon (e.g., description). Difficulty in assembling the phonological strings for outputting was evidenced in articulatory revisions. Word and phrase reformulations reflect similar problems at a concept use level (e.g., I like every did, he did everything).

Subject 2. Medical History. Subject 2 is a 69 year old conduction aphasic male who suffered a left hemisphere parieto-occipital infarct 63 months prior to his participation in this study.

Speech/Language Data. Subject 2's overall percentile ranking on the PICA (Porch, 1981) was at the 72nd percentile. His overall rating on the BDAE (Goodglass \& Kaplan, 1983) was 4 which indicates "a reduction of speech fluency with mild impairment reduction in the ability to express ideas." This rating indicates he is capable of conversing successfully about everyday topics with little-to-no assistance, but the reduction of speech and/or auditory comprehension may make conversing about topics of a 
more complex or unfamiliar nature more difficult.

Word Retrieval Data. Subject 2 produced a total of 52 WRB. These occurred in 23 (46\%) of the T-units examined.

subject 2 used verbal insertions (e.g., I can't say it now because I'm excited), and word and phrase repetitions (e.g., basket, basket persons) to gain more time to retrieve words. Problems in phonological assembly were seen in articulatory reformulations (e.g., [ba] Patton). The high incidence of word and phrase reformulations suggests reduced ability to convey a concept.

\section{Anomic Aphasia Subjects}

The two anomic aphasia subjects produced a total of 124 WRBS which represented $29 \%$ of the total WRBs for the patient sample. Word or phrase reformulation accounted for 58 of the WRBs wih a mean of 29. Articulatory reformulation occurred 16 times, with a mean of 8 . Time fillers and verbal insertions both occurred on 10 occasions, with a mean of 5 .

Subject 3. Medical History. Subject 3 is a 62 year old anomic aphasic male who suffered a subcortical left hemisphere cerebrovascular accident 35 months prior to his participation in this study.

Speech/Lanquage Data. Subject 3's overall ranking on the PICA (Porch, 1981) at the time of his participation in the study placed him at the sixty-fifth percentile in a random sample of left hemisphere damaged adults. His most 
recent assessment with the Minnesota Test for Differential Diagnosis of Aphasia (MTDDA) shows him to score as follows: Auditory Comprehension $=91 \%$, Reading $=98 \%$, Speech $=89 \%$, and Writing $=75 \%$. This is commensurate with his rating of 2 on the Aphasia Severity Scale of the BDAE (Goodglass \& Kaplan, 1983) .

Word Retrieval Data. Subject 3 produced a total of 62 WRBs. These occurred in 19 (38\%) T-units. Ten (52\%) T-units had three or more WRBs.

Although subject 3 had a wide range of WRBs, most were word or phrase reformulation. In the 8 T-units containing three or more WRBs, the target was evenly divided between a concept and a specific word. In every case, subject 3 eventually retrieved the target word or phrase successfully.

Subject 4. Medical History. Subject 4 is a 56 year old anomic aphasic male who suffered a left hemisphere parieto-occipital hemorrhage, 39 months prior to this study.

Speech/Lanquage Data. Subject 4's overall ranking on the PICA (Porch 1981) at the time of his participation in this study placed him at the fifty-eighth percentile in a random sample of left hemisphere damaged adults. His rating of 3 on the Aphasia Severity scale of the BDAE (Goodglass \& Kaplan, 1983) suggests that he can "discuss everyday problems with little or no assistance."

Word Retrieval Data. Subject Subj. 4 produced a total of 62 WRBs. These occurred in 28 (56\%) of the T-units. Ten 
(20\%) T-units contained 3 or more WRBs.

The majority $(84 \%)$ of WRBs were from three categories: word or phrase reformulation (47\%), word or phrase repetition (11\%), and articulatory reformulation (26\%).

\section{Broca's Aphasia Subjects}

Subject 5. The Broca's aphasia subject produced 119 WRBs, representing $27 \%$ of the total WRBs for all subjects. Again, word or phrase reformulation was the most frequently used WRB with a total of 39 occurrences. Word or phrase repetition occurred 27 times, articulatory reformulation 18 times, and generalizations 7 times.

Medical History. Subject 5 is a 62 year old Broca's aphasic male who suffered a left hemisphere thromboembolic cerebrovascular accident 37 months prior to participating in this study.

Speech/Language Data. At the time of this study, Subject 5's overall percentile ranking on the PICA (Porch, 1981), was at the 62nd percentile. His performance on the BDAE (Goodglass \& Kaplan, 1983) gave him a rank of 2 which would indicate that he is capable of conversing about familiar subjects with help from his communication partner.

Subject 5 is not a fluent speaker, but he produces a large quantity of speech. His verbal output, however, is compromised by a concomitant apraxia of speech, and word retrieval problems. Articulation (particularly complex multi-syllabic words) is awkward and frequently off target. 
His prosody is markedly disrupted, perhaps in an effort to compensate for his articulation errors.

Word Retrieval Data. Subject 5 produced a total of 119 WRBs in $29(58 \%)$ of the T-units. Seventeen (34\%) T-units contained three or more WRBs. These were distributed in eleven categories, but predominently involved verbal insertions (10\%), word or phrase reformulations (33\%), word or phrase repetitions (23\%), articulatory reformulations (15\%), and generalizations (6\%).

Use of verbal insertions (e.g., It won't start right now) and word or phrase repetitions (e.g., I started there, I started there) indicate difficulty retrieving information from the semantic lexicon. Problems mapping items from the semantic lexicon on to their phonological shapes in the phonological lexicon are seen in the "tip of the tongue" behaviors exhibited in his generalizations (e.g., the whole thing of the whole place). Apraxic difficulties (motor programming disrhythmias) account for his frequent articulatory revisions (e.g., [ree] navy).

\section{DISCUSSION}

Discussion of Individual subjects

This study focused first on how frequently specific WRBs were employed by conduction, anomic, and Broca's aphasic adults. The second area of focus was the determination of whether or not some WRBs would result in 
the production of the desired word more often than others.

\section{Conduction Aphasia}

Subject 1. Subject 1 reformulates words and phrases to convey concepts successfully, but does less well using these tactics in producing specific words. Words that are most difficult to retrieve are often multi-syllabic or infrequently used (e.g., Kuwait, democracy) in English. When subject 1 encounters difficulty at the semantic level (e.g., delays), he will often break down at one or both of the other two levels as well. On the two occasions in which he did come up with a specific target word, his efforts were not preceded by processing delays.

a. Semantic Lexicon. Subject 1 may benefit from treatment designed to strengthen knowledge of semantic fields. The Feature Analysis program recently described by Massaro and Tompkins (in press) may be useful. Here the client is provided a concept (e.g., cars) and asked to provide information about its semantic features. These features could be further divided into categories such as group membership (transportation), actions (speed, handling), use (racing, family transportation), location (race track, highway), properties (engine size, body style), and associations (makes me think of Indy Five Hundred, family outings).

Semantic paraphasic errors might be addressed by following the suggestions of Hillis (1991). This program 
assists the client in distinguishing among members of a particular category. For example, if the client says "table" instead of "chair," he may be asked to draw a chair, and point out the differences between the two objects. For those frequently used words subject 1 could be taught mnemonic recall strategies. As a bridge from the semantic to the phonological lexicon, auditory-word-picture matching tasks may be helpful.

b. Phonological Lexicon. Access to the phonological lexicon could be facilitated with hierarchical problem solving strategies that would assist subject 1 in the retrieval of the components of the word. For example, he could be asked to think of the number of syllables in the word, its first sound, or a rhyming word. If unable to provide this information, he could be given a choice of words (either written, spoken or both) from which he would select the target word.

Subject 2. Although subject 2 has mild word retrieval difficulty, his conversation breaks down when he attempts to convey complex ideas or needs to produce a multi-syllabic word. Frequently, difficulty retrieving the word from the semantic lexicon is followed by difficulty at the phonological assembly level.

a. Semantic Lexicon. Subject 2 needs treatment tasks that require him to access semantic representations. An example would be category sorting tasks (pictures or words). 
Here, the client sorts stimuli into semantic categories (e.g., fruits, transportation). He then discusses the reasoning behind the placement of each picture within the category (Von Stockert, 1978). The Features analysis program (Massaro \& Tompkins, in press), described earlier, may also facilitate accessing of words and semantic features of concepts. For those words subject 2 attempted to retrieve frequently but found difficult, mnemonic self cueing strategies could be taught.

b. Phonetic Assembly. Subject 2 is successful in many of his self correction efforts. He tends to "work through" many of his phonological assembly problems. He might improve further with the use of repetition drills, particularly on contrastive pairs (e.g., vase, face), repetition of nonsense syllables (e.g., vo, vu), and oral reading. Clinician reinforcement for productive self correction in conversation may also be helpful.

\section{Anomic Aphasia}

Subject 3 . Subject 3 breaks down when he is attempting to convey complex thoughts or to use uncommon words. This is seen by the high number of word and phrase reformulations (e.g., my degree doesn't, wasn't for, well I don't have a degree for that).

a. Semantic Lexicon. Since subject 3 can provide information about the target word, his ability to retrieve words might be improved by teaching him to give more 
detailed descriptive information about the target word (Hillis, 1991). He might also benefit from asking for more time, or using silent pauses. Sometimes subject 3 depends on his communication partner to provide the target word for him. If he took more time to retrieve the word himself, this may not be necessary. Subject 3 needs to work on being "less wordy" and calling attention to his deficits. Delay strategies may help.

Subject 4. Subject 4's primary difficulty is accessing the semantic lexicon. Once he "pulls" the word from the system, he may have further difficulties, but he usually retrieves it. His ability to retrieve the desired word often occurs on an all or none basis. When he encounters difficulty, he might profit from using delay tactics first. stalling for more time could be accomplished by asking for time, or using filled or unfilled pauses. If extra time does not aid retrieval, subject 4 could be encouraged to supply whatever information he possesses about the word (e.g., first sound, what it sounds like, number of syllables), to gesture, or to describe (e.g., the kind of animal that is black and white and looks like a horse). This may help subject 4 retrieve the word or help his listener fill in the blank. If this does not occur, phonological and descriptive information will provide the listener or clinician with enough information to guess the target word. Then subject 4 could be asked to select the 
correct word which was included in a list of words. Several branching steps are then possible. Among these tasks would be writing the word, giving functions of the word, supplying antonymic responses, rhymes, and using the word in a sentence.

\section{Broca's Aphasia}

Subject 5 . Subject 5 has equal difficulty (and success) with retrieval of words and phrases. Selecting words from the semantic lexicon, especially numbers, days of the week and months, and familiar multi-syllabic words, are, by his admission, difficult. Developing a concept is also a problem because of Subject 5's apraxic difficulties. He also speaks rapidly which reduces both word retrieval and motor planning time, compromising his intelligibility.

a. Speech Rate. Treatment for subject 5 should initially focus on reducing his speech rate. By using a pacing board or delayed auditory feed back, subject 5 might be taught to reduce his speech rate to a level that would improve intelligibility. A reduced rate may also give Subject 5 more time to retrieve the desired semantic target, and more time to achieve the articulatory positions. This would allow more processing time, and perhaps improve kinesthetic and auditory monitoring.

b. Semantic Lexicon. Because numbers, days of the week, and months are particularly difficult for subject 5, a chaining technique (e.g., retrieving the number three by 
counting "one, two, three, three guys were playing ball") might be beneficial for subject 5 . Further treatment in this area could include the von stockert's (1978) treatment technique of relating words to a specific category (e.g., things measured in years, things measured in days), combined with the Hillis (1991) technique of identifying the differences between the categories (e.g., years are much longer than days).

c. Phonological Lexicon. Subject 5 could be taught to use word analysis skills: These would involve identifying the number of syllables, the first sound, or any other part of the word he may recall. He could then be asked to produce words that rhyme or begin or end with a specific sound or group of sounds.

d. Apraxic Errors. A written list of words he finds difficult could be collected and used as a drill task, first as single words or contrastive pairs of words, and then as parts of phrases.

\section{GENERAL DISCUSSION}

Results of this study appear to indicate that examination of the WRBs employed by aphasic adults provides additional insight into the communication deficits experienced. Once this information becomes available, remediation that specifically addresses the problem can be developed and the time allotted to word retrieval 
remediation can be used more effectively.

Completion of this study involved extensive preparation. No information could be found that would indicate that a study of this specific a nature had been undertaken in the past. It was necessary, therefore, to develop the procedures needed to carry it out. The first task involved determining a subject profile. The next task was to develop a standardized method of collecting WRBs from conversational speech samples. It was first thought that the speech sample would need to be quite lengthy. After reviewing German's (1992) study, this belief was found to be inaccurate and only 50 T-units from the transcribed conversation were actually analysed.

Another question to be answered involved the identification of WRB types. When the video tapes and transcripts were studied, it was determined that the classification of WRBs in the past were too limited, and, in the case of delay, were too broad. The characteristics of WRBs were examined closely and descriptions were made so that accurate definitions could be developed. Terminology that best fit these definitions was then chosen. At about this stage of the study, information was obtained concerning a similar study which examined the WRBs of children (German \& Glasnapp, 1990). For the sake of uniformity, the terms used in the present study were then modified to match terms in the German Glasnapp article. 
The last aspects of the study to be developed were reliable methods of collecting and managing data. A data collection form was developed, the data collected, and graphs and charts were designed to concisely display the information obtained.

Although developing a WRB profile can be valuable, one must determine the feasibility of applying these procedures to client remediation. The most serious disadvantage is the amount of time involved. The speech/language pathologist must first undergo 4 to 6 hours of training to be able to administer the procedure to aphasia clients. And when using the procedure, a conversation sample must be video taped, accurately transcribed, and the WRBs identified and classified.

Further investigation of WRB is needed. It is hoped that others who follow will use the information in this study as a basis for future studies to possibly identify other types of WRB, and to develop more precise definitions of the WRBs identified in this study (e.g. is 6 seconds an accurate critera for identifying a silent pause?). Since the subjects in this study were all men, it is suggested that future studies include women. It is also hoped that word retrieval remediation programs will be developed to address specifically the characteristics of the deficits found at each level of the word retrieval process. 
CHAPTER V

SUMMARY AND IMPLICATIONS

\section{SUMMARY}

Word retrieval difficulties are experienced by almost all aphasic adults. Consequently, these problems receive a substantial amount of attention in aphasia treatment. Because of the methodological difficulties, few studies have examined WRBs in conversational speech, focusing instead on confrontational naming tasks in which the client is asked to retrieve a specific word. These studies have left unanswered questions about the processes.

The purpose of this study was first to determine how often each specific WRB is employed by conduction, anomic, and Broca's aphasic aduls. There appears to be few differences in the most frequently used WRBs between subjects or aphasic types. Word or phrase reformulation was the most frequently used WRB. Verbal insertion, word or phrase repetition and articulatory reformulation were also prevalent.

The second purpose of this study was to determine if some WRBs result in production of the desired word more often than others for each of the three aphasia types. This question proved to be unanswerable within the confines of 
this study due to the fact that it was not possible to determine whether use of specific WRB led to producion of the target word.

After reviewing the results of this study, it seems promising that WRB profiles of aphasic adults may be developed and examined for evidence that reflects where the subject is having difficulty in the word retrieval process. This information may be useful in the determination of potential treament.

Each subject participated in a videotaped 15 minute conversation during which the experimenter introduced topics in the order specified from a list of topics. These conversations were then transcribed verbatim, and 50 T-units were randomly selected for analysis. The types of WRB employed by the subjects within each T-unit were identified and the following computations were made: (1) total number of WRBs for all T-units, (2) number of WRBs for each category for all T-units, (3) number of T-units containing one or more WRBs, (4) number of T-units containing three or more WRBs, and (5) number of times in T-units containing three or more WRBs led to evocation of a desired word or concept by the subject.

Five aphasic adult subjects from Portland Veterans Affairs Medical Center (PVAMC) participated in this study. These subjects were neurophysiologically stable, within the mid-range of severity and representative of three common 
aphasic syndromes, conduction aphasia $(\mathrm{N}=2)$, anomic aphasia $(N=2)$, and Broca's aphasia $(N=1)$.

\section{IMPLICATIONS}

\section{Clinical Implications}

This study has shown that it is possible to analyze the WRBs aphasic adults employ during conversational speech. Although such a process requires training initially, and additional time is needed to complete an assessment, the speech/language pathologist gains invaluable information that can be directly applied to remediation design. Less time will be spent finding tasks that seem to be beneficial thus reducing the chance that both the client and clinician will become frustrated with tasks that are a "poor fit." Formal WRB assessment may not be cost effective for general use. However, once the clinician is trained in WRB identification, informal notations can be made during brief conversation.

\section{Research Implications}

Further investigation of WRBs is needed. It is hoped that other investigators who follow will use the information in this study as a beginning to possibly identify other types of WRBs, and to develop more precise definitions of WRBs (e.g. is six seconds an accurate critera for identifying a silent pause?). Since the subjects were all men, it is suggested that future studies include women. 
Future studies could replicate these procedures using a population large enough to make statistical analysis applicable. It is also hoped that word retrieval remediation programs will be developed to address the characteristics of deficits found at each level of the word retrieval process.

As more is learned about the brain, aphasiologists are becoming more hesitant to use descriptions of anatomical structure insults to develop an aphasia profile. studies which describe the behaviors the client is exhibiting appear to be helpful in contributing insight into the problem. 


\section{REFERENCES}

Alajouanine, T. (1954). Verbal realization in aphasia. Brain, $79,1-28$.

Bartin, M. I. (1971). Recall of generic properties of words in aphasic patients. Cortex, 7, 73-82.

Benson, D. F., \& Geschwind, N., (1964). The aphasias and related disturbances. Clinical Neurology, 1, 1-25.

Berman, M., \& Peele, L. (1967). A method of aiding aphasic patients. Journal of speech and Hearing Disorders, 32, 372-376.

Blumstein, S. (1981). Phonological aspects of aphasia. In M. T. Sarno (Ed.), Acquired aphasia (pp.129-155). New York: Academic Press.

Brookshire, R. H., (1986). An introduction to aphasia (3rd ed.). Minneapolis, Minnesota: BRK Publishers.

Buckingham, H. W., JR. (1981). Lexical and semantic aspects of aphasia. In M. T. Sarno, (Ed.), Acquired Aphasia (pp. 183-214). New York: Academic Press.

Chapey, R. (1986). Cognitive intervention: Stimulation of cognition, memory, convergent thinking, divergent thinking and evaluative thinking. In R. Chapey (Ed.), Language Intervention strategies in adult aphasia (2nd ed., pp. 215-238). Baltimore: Williams \& Wilkins.

Code, c. (1989). Symptoms, syndromes, models: The nature of aphasia. In C. Code (Ed.), The characteristics of aphasia (pp. 1-22). New York: Taylor \& Francis.

Damasio, A. (1981). Cerebral localization of the aphasias. In M. T. Sarno (Ed.), Acquired aphasia (p. 51-65). New York: Academic Press.

Darley, F. (1982). Aphasia. Philadelphia: W. B. Saunders Company.

Davis, G. A., (1983). A survey of adult aphasia. Edgewood Cliffs: Prentice-Hall, Inc. 
Davis, G. A., \& Wilcox, M. J. (1985). Adult aphasia rehabilitation: Applied pragmatics. San Diego: College-Hill Press.

Eisenson, J. (1973). Adult aphasia assessment and treatment. Englewood cliffs: Prentice-Hall.

Farmer, A., (1977). Self-correction strategies in the conversational speech of aphasic and nonaphasic brain damaged adults. Cortex, 13, 327-334.

Farmer, A., O'Connell, P. F., \& O'Connell, E. J. (1978). Sound error self-correction in the conversational speech of nonfluent and fluent aphasics. Folia Phoniatia, 30, 293-302.

German, D. J. (1992). Test of Word-finding in Discourse. Allen, Texas: DLM Pub.

German, D. J., \& Glasnapp, D. R. (1990). The test of word-finding in discourse: Diagnostic utility evidence. Educational and Psychological Measurement 50 383-392.

Goldfarb, R., \& Halpern, H. (1989). Impairments of naming and word-finding. In $C$. Code (Ed.), The characteristics of aphasia (pp. 33-52). New York: Taylor \& Francis.

Goodglass, H., \& Blumstein, S. (1973). Psycholinguistics and aphasia: Historical context and current problems. In H. Goodglass, S. Blumstein (Eds.), Psycholinguistics and aphasia (pp. 3-9). Baltimore: The Johns Hopkins University Press.

Goodglass, H., \& Kaplan, E. (1983). The assessment of aphasia and related disorders (2nd ed.). Philadelphia: Lea \& Febiger.

Goodglass, H., Wingfield, A., \& Wayland, S. (1989). The nature of prolonged word search. Brain and Language. $36,411-419$.

Hillis, A. G. (1991). Effects of separate treatments for distinct impairments within the naming process.

Clinical Aphasiology, 19, 255-266.

Hunt, K. W. (1965). Grammatical structures written at three grade levels, (Research Report No. 3). Champaign, Illinois: National Council of Teachers of English. 
Kearns, K. P., (1990). Broca's aphasia. In L. L. LaPointe (Ed.). Aphasia and related neurogenic language Disorders (pp. 1-37). New York: Thieme Medical Publishers, Inc.

Lesser, R. (1987). Cognitive neuropsychological influences on aphasia therapy. Aphasiology, 1, 189-200.

Marshall, R. C. (1976). Word retrieval of aphasic adults. Journal of Speech and Hearing Disorders, 41, 444-451.

Marshall, R. C., \& Tompkins, C. A. (1982). Verbal self-correction behaviors of fluent and nonfluent aphasic subjects. Brain and Language, 15, 292-306.

Massaro, M., \& Tompkins, C.A. (In press). Feature analysis for treatment of head injured patients. Clinical Aphasiology.

Nicoloso, L., Harryman, E., \& Krescheck J. (1989). Terminology of communication disorders speechlanguage-hearing ( $3 \mathrm{rd}$ ed.). Baltimore: Williams \& wilkins.

Norlin P. F. (1986). Familiar faces, sudden strangers: Helping families cope with the crisis of aphasia. In R. Chapey (Ed.), Language intervention strategies in adult aphasia (2nd ed., pp. 174-186). Baltimore: williams \& Wilkins.

Porch, B. E. (1981). Porch Index of Communication Ability (Vol. 2, 3rd ed.). Palo Alto, California: Consulting Psychologists Press.

Sarno, J. (1981). Emotional aspects of aphasia. In M. T. Sarno (Ed.), Acquired aphasia (pp. 465-484). New York: Academic Press, Inc.

Schuell, H., \& Jenkins, J. J. (1961). Reduction of vocabulary in aphasia. Brain, 84, 243-261.

Scott, C.M. (1988). Spoken and written syntax. In M. Nippold (Ed.), Later language development Ages 9 through 19 (pp. 49-95). Boston: Little, Brown.

Seron, X., Deloche, G., Bastard, V., Chassin G. \& Hermand, N. (1979). Word difficulties and learning transfer in aphasia patients. Cortex 15, 149-155. 
Simmons, N. (1990). Conduction Aphasia. In LaPointe L.L. (Ed.), Aphasia and Related Neurogenic Language Disorders (pp. 54-77). New York: Thieme Medical Publishers, Inc.

Tompkins, C. A., \& Marshall, R. C. (1982). Communicative value of self-cues in aphasia. Clinical Aphasiology Conference Proceedings, 75-82.

Von Stockert, T. R. (1978). A standardized Program for aphasia therapy. In I. Lebrun \& R. Hoops (Eds.), The Management of Aphasia (pp. 97-107). Amsterdam: Swets \& Zeitlinger BV Pub.

Weigle-Crump, C., \& Koenigsknecht, R.A. (1973). Tapping the lexical store of the adult aphasic: Analysis of the improvement made in word retrieval skills. Cortex, IX, 410-417.

Wepman, J. M. (1976). Aphasia: Language without thought or thought without language? ASHA Legislative Council Report, 18, 131-136.

Wepman, J. M. (1972). Aphasia therapy: A new look. Journal of Speech and Hearing Disorders, 37, 203-214.

Wepman, J. M., Jones, L. V., Bock, R. D. , \& Van Pelt D. (1960). Studies in aphasia: Background and theoretical formulations. Journal of Speech and Hearing Disorders, $25,323-333$.

Wettz, R. T. (1985). Neuropathologies of speech and language. In D. F. Johns (Ed.), Clinical management of neurogenic communicative disorders (2nd ed., pp. 1-96). Boston: Little, Brown and co.

Wertz, R. T. (1984). Language disorders in adults: State clinical of the art. In A. L. Holland (Ed.), Language Disorders in Adults (pp. 1-78). San Diego, California: College-Hill Press. 
APPENDIX A

PORTLAND STATE UNIVERSITY

PERMISSION LETTER 
INFORMED CONSENT

$I$, hereby agree to serve as a subject in the research project to study the word retrieval behaviors of aphasic adults entitled "Type and Effectiveness of Word Retrieval Behaviors Employed by Aphasic Adults Durng Conversational Speech" conducted by Priscilla J. Blake under the supervision of Dr. Robert C. Marshall.

I understand that in this study, I will be asked to talk about topics which are of general interest to most adults. I will be expected to attempt to come up with words which are "on the tip of my tongue," without assistance.

I understand that there are no risks to me personally. It will, however, take about an hour and one half of my time.

It has been explained to me that the purpose of this study is to learn the types and successfulness of the word retrieval behaviors employed by aphasic adults.

I may not receive any direct benefit from participation in this study, but my participation may help to increase knowledge which may benefit others in the future.

Priscilla Blake has offered to answer any questions I may have about the study and what is expected of me in the study. I have been assured that all information I give will be kept confidential and neither my name nor identity will be used for publication or public discussion purposes.

I understand that my participation in this study is purely voluntary. Should I choose not to participate, or should I choose to withdraw from participation once the study has begun, my relationships with either Portland State University or the Department of Veteran's Affairs will not be jeopardized.

I have read and understand the foregoing information and agree to participate in this study.

Date

Signature

If you experience problems that are the result of your participation in this study, please contact the chair of the Human Subjects Research Review Committee, Office of Grants and Contracts, 303 Cramer Hall, Portland State University, 725-3417. 
APPENDIX B

PORTLAND VA MEDICAL CENTER

PERMISSION LETTER

(STROKE SUBJECTS) 
Priscilla J. Blake

Robert C. Marshall. Ph.D., CCC-SLP

Speech-Language Pathology

Portland VA Medical Center

Portland, OR, 97207

(503) 220-8262 $\times 5714$

$10-1086$

INFORMED CONSENT

Type and Effectiveness of Word Retrieval Behaviors Employed by Aphasic Adults During Conversational Speech

(Stroke subjects)

1. The purpose of this study is to gather information about the types and effectiveness of word retrieval behaviors used by adult aphasics when attempting to come up with a word during conversational speech. I understand that I have been selected for this study because I have been diagnosed as having had a stroke.

Priscilla Blake has explained the details of the study to me and has given me an opportunity to ask questions. I will be asked to engage in conversation with an examiner on a series of topics familiar to me. The examiner will refrain from providing a word which may be on the "tip of my tongue," but difficult for me to produce. I will be expected to search for that word on my own. Both video and audio recordings will be made of the conversations so that the examiner will be able to study them and collect the data needed to complete the study.

2. I understand that there is no physical risk or discomfort involved.

I understand that there is no direct benefit of this procedure to me, but that the study may enhance the ability of speech-language pathologists to work with people who have had strokes.

3. I consent to the use of the results of this study for publication for scientific purposes. I understand that I will not be identified in any way in publications or presentations resulting from the study.

4. I understand that refusal to participate in the study will not affect my VA benefits or the treatment I receive at the VA. I also understand that I am free to withdraw from the study at any time without affecting my VA benefits. Every reasonable effort to prevent any injury that could result from this study will be taken. 
In any event of physical injuries resulting from this study, medical care and treatment will be available at this institution. For eligible veterans, compensation damages may be payable under 38 USC 251 or in some circumstances, under the Federal Tort claims Act. For non-eligible veterans and non-veterans, compensation would be limited to situations where negligence occurred and would be controlled by the provisions of the Federal Tort Claims Act. For clarification of these laws, contact District Counsel at (503) 326-2441. I have not waived any legal rights or released the hospital or its agents from liability for negligence by signing this form.

5. Therefore, having given consideration to the above information, I voluntarily consent to participate in this study as described.

Signature of Volunteer

Signature of Witness
Date

Witness (print)

Signature of Investigator 


\section{APPENDIX C}

PORTLAND VA MEDICAL CENTER

PERMISSION LETTER

(SPOUSE/GUARDIAN) 
Priscilla J. Blake, B.S.

Robert C. Marshall, Ph.D., CCC-SLP

Speech-Language Pathology

Portland VA Medical center

Portland, OR 97207

(503) $220-8262 \times 5714$

$$
10-1086
$$

INFORMED CONSENT

Type and Effectiveness of Word Retrieval Behaviors Employed by Aphasic Adults During Conversational speech (Spouse/Guardian)

1. The purpose of this study is to gather information on the types and effectiveness of word retrieval behaviors used by adult aphasics when attempting to come up with a word during conversational speech. I understand that my spouse/ward was selected for this study because he/she has been diagnosed with a stroke.

Priscilla Blake has explained the details of the study to my spouse/ward and to myself and has given us an opportunity to ask questions. MY spouse/ward will be asked to engage in conversation with an examiner on a series of topics familiar to him/her. The examiner will refrain from providing a word which may be on the "tip of his/her tongue," but difficult to produce. He/she will be expected to search for that word on his/her own. Both video and audio recordings will be made of the converstions so that the examiner will be able to study them and collect the data needed to complete the study.

2. I understand that there is no physical risk or discomfort involved. I understand that there is no direct benefit of this procedure to my spouse/ward, but that the study may enhance the ability of speechlanguage pathologists to work with people who have had strokes.

3. I consent to the use of the results of this study for publication for scientific purposes. I understand that my spouse/ward will not be identified in any way in publications or presentations resulting from the study.

4. I understand that refusal to participate in the study will not affect my spouse/ward's VA benefits or the treatment my spouse/ward receives at the VA. I also understand that my spouse/ward may withdraw from the study at any time without affecting his/her VA benefits. 
Every reasonable effort to prevent any injury that could result from this study will be taken. In the event of physical injuries resulting from the study, medical care and treatment will be available at this institution. For eligible veterans, compensation damages may be payable under 38 USC 251 or, in some circumstances, under the Federal Tort claims Act. For non-eligible veterans and non-veterans, compensation would be limited to situations where negligence occurred and would be controlled by the provisions of the Federal Tort claims Act. For clarification of these laws, contact District Counsel (503) 326-2441. I have not waived any legal rights or released the hospital or its agents from liability for negligence by signing this form.

5. Therefore, having given consideration to the above information, I voluntarily consent for my spouse/ward to participate in this study as described.

Spouse/Guardian's Signature

Signature of witness
Date

Witness (print)

Signature of Investigator 
APPENDIX D

CONVERSATIONAL PERIOD TOPICS 


\section{CONVERSATIONAL PERIOD TOPICS}

1. Current events

2. Price of gas

3. Armed service experience

4. Job

5. Jobs held as a young man/woman

6. First car

7. Family (parents and siblings)

8. The old days

9. Family (spouse and children)

10. Pets

11. Sports

12. Interests and hobbies

13. Travel and vacation

14. Pet peeves

15. Favorite foods

16. Favorite TV shows

17. What you do around the house 


\section{APPENDIX E}

WORD RETRIEVAL BEHAVIORS DATA COLLECTION FORM 
WORD RETRIEVAL BEHAVIORS DATA COLLECTION FORM

SUBJECT :

\begin{tabular}{|c|c|c|c|c|c|c|c|c|c|c|c|c|c|c|c|}
\hline & 1 & 2 & 3 & 4 & 5 & 6 & 7 & 8 & 9 & 10 & 11 & 12 & 13 & 14 & $\mathrm{TL}$ \\
\hline 1 & & & & & & & & & & & & & & & \\
\hline 2 & & & & & & & & & & & & & & & \\
\hline 3 & & & & & & & & & & & & & & & \\
\hline 4 & & & & & & & & & & & & & & & \\
\hline 5 & & & & & & & & & & & & & & & \\
\hline 6 & & & & & & & & & & & & & & & \\
\hline 7 & & & & & & & & & & & & & & & \\
\hline 8 & & & & & & & & & & & & & & & \\
\hline 9 & & & & & & & & & & & & & & & \\
\hline 10 & & & & & & & & & & & & & & & \\
\hline 11 & & & & & & & & & & & & & & & \\
\hline 12 & & & & & & & & & & & & & & & \\
\hline 13 & & & & & & & & & & & & & & & \\
\hline 14 & & & & & & & & & & & & & & & \\
\hline 15 & & & & & & & & & & & & & & & \\
\hline 16 & & & & & & & & & & & & & & & \\
\hline 17 & & & & & & & & & & & & & & & \\
\hline 18 & & & & & & & & & & & & & & & \\
\hline 19 & & & & & & & & & & & & & & & \\
\hline 20 & & & & & & & & & & & & & & & \\
\hline 21 & & & & & & & & & & & & & & & \\
\hline 22 & & & & & & & & & & & & & & & \\
\hline 23 & & & & & & & & & & & & & & & \\
\hline 24 & & & & & & & & & & & & & & & \\
\hline 25 & & & & & & & & & & & & & & & \\
\hline P1 TL & & & & & & & & & & & & & & & \\
\hline P2 TL & & & & & & & & & & & & & & & \\
\hline TOTAL & & & & & & & & & & & & & & & \\
\hline
\end{tabular}


WORD RETRIEVAL BEHAVIORS DATA COLLECTION FORM

PAGE 2

\begin{tabular}{|r||l|l|l|l|l|l|l|l|l|l|l|l|l|l|l||}
\hline & 1 & 2 & 3 & 4 & 5 & 6 & 7 & 8 & 9 & 10 & 11 & 12 & 13 & 14 & TL \\
\hline 26 & & & & & & & & & & & & & & & \\
\hline 28 & & & & & & & & & & & & & & & \\
\hline 29 & & & & & & & & & & & & & & & \\
\hline 30 & & & & & & & & & & & & & & & \\
\hline 31 & & & & & & & & & & & & & & & \\
\hline 33 & & & & & & & & & & & & & & & \\
\hline 34 \\
\hline 35 \\
\hline 36
\end{tabular}




\section{APPENDIX F}

WORD RETRIEVAL BEHAVIORS NUMERICAL CODES 
WORD RETRIEVAL BEHAVIORS NUMERICAL CODES

1 - Prolonged Pause

2 - Time Filler

3 - Combination Prolonged Pause and Time Filler

4 - Verbal Insertion

5 - Request for Time

6 - Gestural or oral Sound Insertion

7 - Word or Phrase Reformulation

8 - Word or Phrase Repetition

9 - Articulatiory Reformulation

10 - Gesture or Body Language

11 - Recitation of overlearned Sequences or Chaining

12 - Description

13 - Generalization

14 - Unclassifiable 